\title{
THE EFFECT OF MUSIC ON HEART RATE VARIABILITY (REVIEW)
}

\author{
PARIZEK $\mathrm{D}^{1}$, Sladicekova $\mathrm{K}^{1}$, TONHAJZEROVA $\mathrm{I}^{2}$, Veterník $\mathbf{M}^{1}$, JAKUS $\mathrm{J}^{1}$. \\ ${ }^{1}$ Department of Medical Biophysics, Jessenius Faculty of Medicine in Martin, Comenius University \\ in Bratislava, Slovak Republic \\ ${ }^{2}$ Department of Physiology, Jessenius Faculty of Medicine in Martin, Comenius University in \\ Bratislava, Slovak Republic
}

\begin{abstract}
A b s tract
Music therapy and the use of music in medical practice have now become rapidly advancing and promising areas of non-invasive alternative medicine. However, the opinions of physicians and therapists on the implementation of this complementary therapy, especially in the process of treating the patient, are constantly different. In addition, the effect of music and individual methodological procedures are not uniform and defined in detail. Therefore, this review study summarizes the results and conclusions of some selected high-quality publications over the last decade and makes suggestions for improvement and further research. It focuses mainly on the evaluation of changes in heart rate variability (HRV) as an indicator of the activity of the autonomic nervous system (ANS) in connection with the application of music in the process of passive music therapy.
\end{abstract}

Keywords: music therapy, heart rate variability, review article

"Music is a cure for the suffering of the soul." Quintus Flaccus Horatius

\section{INTRODUCTION}

Music, known as an art form for thousands of years, has become an integral part of modern human life. Thanks to electronic devices free-available on the market we are in contact with music practically every day in different places. There are countless songs of different musical genres and styles. It is already well-known that listening to music subjectively affects not only our emotions and feelings but also higher feelings, moods, and affections. The overall mental balance of an individual thus plays a major role in the aspect of his health.

Modern medicine today prefers an individual, highly specific approach to the patient. With the development of a wide range of diseases of civilization, other diseases and disabilities, non-invasive medicine, in the form of various complementary therapies, has gradually found a place in the process of diagnosis and treatment.

A relatively unexplored area is music therapy, the so-called music therapy. Stimulation of the auditory system with music is gaining more and more attention in the treatment and prevention of disorders (1). According to the currently available evidence in individual studies, music in the individual primarily attracts attention, can suppress a number of emotions, changes or regulates mood, increases work performance, stimulates arousal, induces the

Corresponding author: Ing. Daniel Parizek; e-mail: parizek4@uniba.sk

(C) 2021 Parizek D. et al.

This work is licensed under the Creative Commons Attribution-NonCommercial-NoDerivs 4.0 License (https://creativecommons.org/licenses/by-nc-nd/4.0/) 
functioning of higher nervous functions, regulates inhibitions, supports rhythmic movement, and others (1). Musical auditory stimulation, thus, evokes a diverse range of psychological and hemodynamic expressions by influencing the autonomic regulation of cardiac activity.

The autonomic nervous system is the main regulatory system that ensures flexibility, homeostasis, and adaptability of the body during rest but also in stressful situations. Its centers are located in the cortical (cerebral cortex) and subcortical areas (spinal cord, brain stem, hypothalamus, etc.) and its activity in general cannot be controlled by will. From a functional point of view, it consists of two units: pars sympathica and pars parasympathica, which in principle work antagonistically. This system is involved in the management and control of all vital processes (internal organ activity, homeostasis, smooth muscle function, heart and gland function, metabolism, and vital physiological functions) (2).

Heart rate variability is considered to be one of the most important indicators of autonomic regulation of heart function in the literature. Even in a normal ECG recording, it can be noticed that the time intervals between R-R oscillations are variable. We observe rhythmic oscillations in the heart rhythm. Heart rate variability (HRV) is thus a mirror of the cardiorespiratory control system and is a manifestation of beat-to-beat regulation of the heart pacemaker (Javorka, 1996). The heart rate itself is thus influenced by the activity of the autonomic nervous system and its effect on the sinoatrial node. In simple terms, the overall reduction in HRV is an indicator of poor cardiovascular function, e.g. as in chronic heart failure, while an increase in HRV corresponds to an improvement in cardiovascular function. The HRV analysis method has gradually gained attention for its potential to detect abnormal physiologies.

Musical sound stimulation affects HRV through a neural mechanism that is not yet exactly known $(1,4)$.

In addition, many previous studies have suggested that music therapy has positive effects on HRV in sick patients. However, therapeutic procedures and methods are not uniform and the influence of music is not clear. That is why the opinions of therapeutic specialists and doctors on musical stimulus differ. Clarification of physiological reactions associated with music is an important step for the development and future of music therapy as one of the therapeutic or preventive therapies, for example in the field of cardiovascular disorders. The current insufficient number and quality of studies does not make it possible to unambiguously determine when and under what conditions music therapy is therapeutically effective $(5,6)$.

Therefore, this review study will focus on the analysis of existing data in relation to the effects of music on HRV in the concept of music therapy

\section{METHODS}

The review study consists of full-text articles that were searched in web of science databases via the kopernio application. The kopernio interface collects scientific publications and collaborates with more than 20,000 databases. The articles were searched and selected according to the required criteria within the period from September to October 2020. The keywords music therapy and central nervous system, HRV, and music therapy were searched for priority for selection. On the basis of abstracts and titles, the articles that were not directly related to the topic were excluded, resp. heart rate variability was not examined as a priority as an indicator of ANS activity. References in individual publications for the expansion of electronic search were also independently checked on an ongoing basis.

Review articles and studies that did not contain an abstract or did not provide a complete text in English were excluded. Another criterion in the selection was the time classification of individual publications. Priority was given to basic and clinical studies within the period between 2010 and 2020 which investigated the above-mentioned effect of sound auditory stimulation in connection with the autonomic nervous system. 


\section{RESULTS}

More than 3,190 links related to music therapy and the central nervous system and approximately 17,300 links in music therapy and heart rate variability were found in the electronic search after entering key terms and time parameters. In the second round of the selection, articles and books that were not clearly related in content to the subject of the search for the review study were eliminated. After individual consideration, the titles and abstracts of 45 articles were subjected to a final analysis and a final selection. A search of the list of references for some publications confirmed the absence of relevant documents and, therefore, such work was also excluded. After a highly specific selection a total of 30 most relevant and interesting articles from the last decade were selected for a final processing. A brief overview of selected conclusions of some studies is collected in Tab.1.

\begin{tabular}{|c|c|}
\hline Author and year & Conclusions \\
\hline $\begin{array}{l}\text { Orita et al., } \\
2012(7)\end{array}$ & $\begin{array}{l}\text { The authors showed that music therapy suppressed parasympathetic } \\
\text { nervous activities and can trigger the dominant state of sympathetic } \\
\text { nervous activities in patients with severely and multiply disabled children } \\
\text { and that the frequency domain analysis of HRV could be a powerful tool for } \\
\text { the objective evaluation of music therapy. }\end{array}$ \\
\hline $\begin{array}{l}\text { Martiniano et al., } \\
2017 \text { (8) }\end{array}$ & $\begin{array}{l}\text { Musical auditory stimulus intensified HR autonomic responses to anti-hy- } \\
\text { pertensive medication in well-controlled hypertensive subjects. }\end{array}$ \\
\hline $\begin{array}{l}\text { Chih-Yaun Chuang } \\
\text { et al., } 2010 \text { (5) }\end{array}$ & $\begin{array}{l}\text { This study provides a preliminary evidence that music therapy may be clini- } \\
\text { cally useful for promoting relaxation sensation and increasing parasympa- } \\
\text { thetic nervous system activity in treated cancer survivors. }\end{array}$ \\
\hline $\begin{array}{l}\text { Raglio et al., } \\
2015 \text { (9) }\end{array}$ & $\begin{array}{l}\text { In conclusion, a more methodological rigor and a clear definition of music } \\
\text { approaches are needed to improve the quality of music therapy research } \\
\text { and to focus on the specific role of music-based interventions in psycho- } \\
\text { logical symptoms in the field of neurology. }\end{array}$ \\
\hline $\begin{array}{l}\text { Ziya Tan et al., } \\
2015 \text { (10) }\end{array}$ & $\begin{array}{l}\text { The authors showed and emphasized that, as in other studies, the heart- } \\
\text { beat and HRV of patients ( }=50 \text { ) listening to a music sample of their own } \\
\text { choice during scintigraphy were significantly lower than in the control } \\
\text { group (without music). }\end{array}$ \\
\hline $\begin{array}{l}\text { Ribeiro et al., } \\
2018 \text { (11) }\end{array}$ & $\begin{array}{l}\text { Music therapy had a significant and positive impact on anxiety and depres- } \\
\text { sion, acting on prevention of cardiovascular diseases. }\end{array}$ \\
\hline $\begin{array}{l}\text { Archana et al., } \\
2016(12)\end{array}$ & $\begin{array}{l}\text { This study provides a preliminary evidence that listening to preferential } \\
\text { music could be an effective method of relaxation, as indicated by a shift of } \\
\text { the autonomic balance towards the parasympathetic activity among medi- } \\
\text { cal students. }\end{array}$ \\
\hline $\begin{array}{l}\text { Roque at. al., } \\
2013 \text { (13) }\end{array}$ & $\begin{array}{l}\text { We suggest that relaxant baroque and excitatory heavy metal music slightly } \\
\text { decrease global heart rate variability because of the equivalent sound level. }\end{array}$ \\
\hline $\begin{array}{l}\text { Amaral et al., } \\
2016 \text { (1) }\end{array}$ & $\begin{array}{l}\text { The researchers focused on different intensities of baroque and heavy metal } \\
\text { music in connection with the heartbeat. They noted that heavy metal and } \\
\text { baroque musical auditory stimulation at lower intensities acutely reduced } \\
\text { global modulation of the heart and only heavy metal music reduced HRV at } \\
\text { higher intensities. They may surmise that HRV elicited by high intensity } \\
\text { heavy metal music was elicited by an autonomic response involved in the } \\
\text { acoustic startle reflex. }\end{array}$ \\
\hline
\end{tabular}




\begin{tabular}{|l|l|}
$\begin{array}{l}\text { Silva at al., } \\
2014(14)\end{array}$ & $\begin{array}{l}\text { The findings of the present study showed that acute exposure to classical } \\
\text { baroque music reduced the sympathetic modulation of the heart, while } \\
\text { excitatory heavy metal music decreased the global variability of the heart } \\
\text { rate. Moreover, the classical baroque music acutely increased HRV in } \\
\text { healthy male subjects. }\end{array}$ \\
$\begin{array}{l}\text { Koelsch et al., } \\
2015 \text { (16) }\end{array}$ & $\begin{array}{l}\text { Music is potentially a low-cost and safe adjuvant for intervention and ther- } \\
\text { apy. However, the effects of music on the heart rate are small and results } \\
\text { of studies on this topic are often inconsistent. }\end{array}$ \\
\hline $\begin{array}{l}\text { Trappe et al., } \\
2016 \text { (17) }\end{array}$ & $\begin{array}{l}\text { Music by Mozart and Strauss lowered the subjects blood pressure and } \\
\text { heart, while music by ABBA did not. Mozart's music had the strongest } \\
\text { effect, the piece used was his Symphony No. 40 in G minor (KV550). }\end{array}$ \\
\hline
\end{tabular}

\section{DISCUSSION}

It is an indisputable fact that music has gradually found its way and application in the field of medicine. We are talking about so-called music therapy as a form of non-invasive approach to the patient. The main goals of therapists in the broadest spectrum are to encourage the patient to express and release their own emotions, to help with stress or anxiety situations associated with everyday life or directly with the diagnosis, to improve mood and, finally, the overall quality of life. As Javorka et al. noted, in addition to the well-known regular physical exercise and sport, various relaxation methods as well as slow breathing training associated with music therapy have been used for a long time in autonomic as well as emotional dysfunction, as well as in the treatment of pain, anxiety symptoms, and other conditions (19).

Surveys point to the fact that the patient does not need skills or talent in the field of music

in order to benefit from music (20). Therefore, it is possible to divide the music therapy approach into passive or active. In this review study we selected articles that examine the impact of music on a person who is a passive object for the application of music and does not perform any active activity in connection with the composition or the creation of musical sounds.

Over the last decade hundreds of „....articles pointing to a great importance of using music in connection with healthy and, above all, especially sick patients have been published. However, these individual publications are very diverse, limited (insufficient number of patients, gender, age, absence of control groups), non-specific in terms of methodological approach, selection, application and effects of individual musical patterns and their analytical description. It is necessary to examine in more detail and then clearly define qualitatively and quantitatively the effect of music on humans for repeatability and increase the credibility of music therapy in medical practice for specific cases. Therefore, one of the most important criteria in the selection of the study was to evaluate the effect of music on humans in connection with the examination of a physiological parameter HRV. This appears in several literature as an important quantifiable indicator of the activity of the autonomic nervous system associated with general homeostasis. It should be noted that this parameter also has its limitations, which need to be comprehensively considered in the evaluation and presentation (RSA, humoral effects, baroreflexes, pharmacological profile, current patient status, etc.).

After studying the particular publications we can say that in all the collected studies there were significant or less significant oscillations of the heart rhythm when listening to music, which were subsequently evaluated most often by the method of frequency analysis (HF, LF, $\mathrm{HF} / \mathrm{LF}$ ). HRV frequency analysis is currently the simplest non-invasive tool for investigating the sympathetic and parasympathetic contribution to overall autonomous management (21). 
A decrease in HRV with a decrease in the activity of the high-frequency component is observable in several physiological as well as pathological situations. Examples are persons with insufficient movement at work, with minimal physical activity, patients with essential hypertension, after myocardial infarction, with diabetes mellitus, and others (19).

After the analysis of the results (LF / HF, RR interval, geometric indices RRTri, SD1, SD2, SD1 / SD2), after considering the limitations, it can be generally concluded that listening to music is clinically useful mainly in promoting relaxation, fatigue reduction, and elimination of depression as evidenced by individual studies that indicated an increase in the activity of the parasympathetic nervous system, e.g. in patients treated for cancer or in mothers of premature babies. $(5,11,25)$. Also interesting is the result of studies that showed a more intense effect of antihypertensive drug treatment on the heart rate in connection with music, even after taking into account that the resting heart rate was already reduced by listening to music (8). It is evident that the influence of music on HRV cannot be denied (Table 2). Also Leubner et. al reported in their 2017 survey study a statistically significant reduction in the degree of depression in patients, always compared to the control group. Using the right method and music literally "trained the parasympathetic," thereby relieving stress, improving hypertension, chronic fatigue, irritable bowel syndrome, and other conditions (22).

Table 2 Percentage of individual types (genres) of music samples in the collected studies and their impact on HRV (positive $\uparrow$, negative $\downarrow$ ) evaluated on the basis of its frequency analysis

\begin{tabular}{|l|c|c|}
\hline & percentage (\%) & HRV change \\
\hline metal vs. classical & 25 & $\downarrow$ \\
\hline noise & 15 & $\uparrow$ \\
\hline music specifc frequency (f) & 15 & depands on $\mathrm{f}$ \\
\hline instrumental (no singning) & 15 & $\uparrow$ \\
\hline pleasant, soft, relaxing & 30 & $\uparrow$ \\
\hline not specified own choice & 5 & $\uparrow$ \\
\hline
\end{tabular}

A relatively frequent limitation of individual studies appears to be a small number of examined individuals, the absence of control groups, or age representation. On the other hand, a significant shift in modern research and music therapy, which is again confirmed by individual publications, is the integration of women during hormonal instability, emotional profile, and other sexual specifics in connection with the observation of heart rate variability. The literature speaks of various cardiovascular and physiological responses when comparing men and women not only in general but also in connection with music therapy (1). Intense stress responses to auditory stimulation were observed in women as in men, and other studies have been conducted on emerging differences in psychophysiological responses due to current hormonal status. Due to the exclusion of the influence of the interference of the follicular and luteal phases of the cycle of women on the autonomic regulation of the heart, it is recommended not to perform the examination within the period between $10^{\text {th }}-15^{\text {th }}$ and $20^{\text {th }}-25^{\text {th }}$ day of the cycle at which the basic non-linear properties of HRV are affected (1). However, research addressing these differences is still insufficient at present. A comparison of the gender distribution from all collected studies where information was available can be seen in Tab. 3 . 
Table 3 Age composition and classification based on gender and health status ( \pm SD)

\begin{tabular}{|l|c|c|c|c|c|c|c|}
\hline & $\mathbf{n}$ & $\%$ & healthy & unhealthy & total & MIN age & MAX age \\
\hline Male & 167 & 30 & & & & & \\
\hline Female & 301 & 55 & 374 & 178 & 552 & $22.67 \pm 10$ & $44.16 \pm 24$ \\
\hline not divided & 84 & 15 & & & & & \\
\hline
\end{tabular}

Our review study shows an increased number of women in passive music therapy research over the last 10 years. We consider this information useful for objectifying the overall results and further studies. Furthermore, more than $67 \%$ of the examined individuals were healthy, it means they did not suffer from any known cardiac dysregulation, functional disorders, acute or chronic diseases that would potentially affect HRV. In addition, healthy probands did not take any drugs and according to the BMI index did not fall into the group of obese or malnourished. Such a group of individuals is considered in several studies to be the most appropriate starting point for clarifying the principle of the degree of influencing the balance of ANS by music, taking into account the appropriate age (early adulthood is the most appropriate).

A great variety of individual studies included in this review is observed in the area of musical stimulus selection. The genre, tempo, volume, duration of the music samples and the methods of the investigation protocol are quite different. HRV is most often observed in the application of two generally different music groups, the effect of "exciting" and, on the other hand, "calming" music in connection with the phases of silence. Koelsch et al. (2015) noted that the same musical stimulus can have both stimulating and relaxing-suppressing effects (16). For example, even at the level of the brainstem, metal beats can provoke stimulating autonomous reactions, while the same composition, on the other hand, has a calming effect on the metal enthusiast (after considering endocrine and immune changes) (1).

In addition, one of the last interesting discoveries is so-called "Mozart effect". According to several Canadian studies the increase in IQ when listening to or playing classical music is valid not only for general but also for spatial intelligence. Dr. Rauscher thus perceives music in her work as a gateway to higher brain functions and is convinced that the "right" music can help us understand the work of the brain, while also positively influencing thinking and creation $(23,24,26)$.

The selection and specification of a music track for a music therapy protocol and a particular individual appear to be very important. Amaral et al. in his study emphasized the importance of subjective composition selection and subsequent caution in interpreting the results obtained, as he noted a diversity in selection in other studies as well. He states that the patients' choice of preferred sedative music resulted in increased dopamine release in the brain's compensatory areas (nucleus accumbens, nucleus caudatus) $(1,13)$.

Furthermore, in the analysis of data and interpretation of the effect of music on humans there is an insufficient physical description of the applied music sample in individual research. Although frequency or time analysis of HRV is the main indicator of ANS in several publications, its changes and association with specific intensities, frequencies, noise, tempo, and duration have not been clarified yet. An interesting and little-explored area is, for example, the influence of music intensity or specifically defined frequencies on HRV and, thus, on ANS. Lee et al. observed a significant interaction between sympathetic cardiac regulation and white noise intensity - the higher the white noise intensity, the higher the LF / HF ratio and the lower the $\operatorname{HRV}(26,27)$. Aravena et al. (2019) observed a significant reduction in the degree of anxiety and fear, as well as a reduction in salivary cortisol levels in patients who underwent tooth extraction while listening to a music track at $432 \mathrm{~Hz}$ compared to the controls (18). 
Next, we present the recommendations and suggestions for the methodological protocol summarized in the points.

- When choosing a musical stimulus for research, allow the individual to choose their own musical stimulus from several pre - prepared musical genres (baroque, metal, jazz, etc.)

- Musical stimuli or a group of stimuli must be clearly characterized in terms of musical, acoustic, and emotional influence (tempo, genre, musical performance, intensity, duration, spectral analysis, power spectral density, frequencies, subjective emotional perception - feeling of excitement / relaxation, etc.)

- Detailed history and description of the individual (BMI, age, sex, health status, etc.)

- Inclusion of control groups in clinical trials with a control stimulus with as many control stimuli as possible

- Inclusion and evaluation of psychological variables (mood / anger / anxiety)

- In patients examined, implement often missing data, e.g. about the length of hospitalization, overall patient satisfaction, intake of sedatives, opioids, and other drugs

- Description of the number and repetition of music therapy meetings in a time scale

- In addition to HRV, consider incorporating ANS-related emotional valence testing, for example, using electrodermal activity measurements, and further integrate voluntarily modified respiration control

- Application of music track, stimulus, samples in an acoustically isolated room

- High-quality comfortable hardware music components (headphones, etc.) and a comfortable position for the patient

\section{CONCLUSION}

Any further study dealing with the application of music to humans and the subsequent observation and evaluation of cardiovascular parameters appears to be very important and useful. In further observation and evaluation of cardiovascular parameters in the process of music therapy, we recommend including a detailed description of the methodological procedure (mainly selection and definition of music sample, current health status of the proband, definition of restrictions, control group, etc.). Music therapy, passive or active, can thus become a recognized and other undisputed therapy and more applied in current medical practice.

\section{REFERENCES}

1. Amaral J, Guida HL, Abreu LC, et al. Effects of auditory stimulation with music of different intensities on heart period. Journal of Traditional and Complementary Medicine 2016; 6: 23-28.

2. Slavikova M, Sekaninova N, Bona OL, et al. Biofeedback - A promising non-pharmacological tool of stress - related disorders. Acta medica martiniana 2020; 20(1):1-8.

3. Javorka K. Clinical physiology for pediatricians (in Slovak). Martin: Osveta; 1996. 487p.

4. Valenti VE, Guida HL, Frizzo ACF, et al. Auditory stimulation and cardiac autonomic regulation. Clinics 2012; 67(8):955-958.

5. Chuang CY, Han WR, Li PC, et al. Effects of music therapy on subjective sensations and heart rate variability in treated cancer survivors: a pilot study. Complement Ther Med. 2010; 18(5): 224-6.

6. Chuang CY, Han WR, Li PC, et al. Effect of long-term music therapy intervention on autonomic function in anthracycline-treated breast cancer patients. Integrat Cancer Ther 2011; 10(4): 312-6.

7. Orita M, Hayashida N, Shinkawa T, et al. Monitoring the autonomic nervous acitivity as the objective evaluation of music therapy for severely and multiply disabled children. Tohoku J.Exp. Med 2012; 227: 185-189.

8. Martiniano EC, Santana MDR, Barros ELD, et al. Musical auditory stimulus acutely influences heart rate dynamic responses to medication in subjects with well-controlled hypertension, Scientific reports 2018; 8:958. 
9. Raglio A, Attardo L, Gontero G, et al. Effects of music and music therapy on mood in neurological patients. World journal of psychiatry 2015; 5(1): 68-67.

10. Tan ZY, Ozdemir S, Temiz A, et. al. The effect of relaxing music on heart rate and heart rate variability during ECG Gated-myocardial perfusion scintigraphy. Complementary therapies in clinical practice 2015; 21: 137-140.

11. Ribeiro MKA, Alcantara-Silva TRM, Oliveira JCM, et al. Music therapy intervention in cardiac autonomic modulation, anxiety, and depression in mothers of preterms: randomized controlled trial. BMC psychology 2018; 6-57.

12. Archana R, Mukilan R. Beneficial effect of preferential music on excercise induced changes in heart rate variability. Journal of clinical and diagnostic research 2016; 10(5): 9-11.

13. Roque AL, Valenti VE, Guida HL, et. al. The effects of auditory stimulation with music on heart rate variability in healthy women. Clinics 2013; 68(7): 960-967.

14. Silva SAF, Guida HL, Antonio AM, et al. Acute auditory stimulation with different styles of music influences cardiac autonomic regulation in men. International cardiovascular research journal 2014; 8(3): 105-110.

15. Thakare AE, Mehrotra R, Singh A. Effect of music tempo on exercise performance and heart rate among young adults. Int J Physiol Pathophysiol Pharmacol 2017; 9(2): 35-39.

16. Koelsch S, Jäncke L. Music and the Heart. European heart Journal 2015; 36: 3043-3048.

17. Trappe HJ, Voit G. The cardiovascular effect of musical genres. Deutsches Arzteblatt International 2016; 113: 347-52.

18. Aravena PC, Almonacid C, Mancilla MI. Effect of music at $432 \mathrm{~Hz}$ and $440 \mathrm{~Hz}$ on dental anxiety and salivary cortisol levels in patients undergoing tooth extraction: a randomized clinical trial. Journal of applied oral science 2020; 28: e20190601.

19. Javorka K. et al. Heart rate variability (in Slovak). Martin: Osveta; 2008. 204p.

20. Wong C. The benefits of music therapy. Verywell mind, 2018. Available: https://www.verywellmind.com/benefits-of-music-therapy-89829?print.

21. Task Force of the European Society of Cardiology and the North American Society of Pacing and Electrophysiology. Heart rate variability: standards of measurement, physiological interpretation and clinical use. Circulation 1996; 93(5):1043-65.

22. Leubner D, Hinterberger T. Reviewing the effectiveness of music interventions in treating depression. Frontiers in Psychology 2017; 8: 1109.

23. Campbell D. Mozartuv efekt. Eminent; 2008. 271p.

24. Hally T. The Mozzart effect. Mensa international Journal 2008; 525.

25. Idrobo-Ávilla EH, Loaiza-Correa H, Noorden L, et al. Different types of sounds and their relationship with the electrocardiographic signal and the cardiovascular system-review. Frontiers in Physiology 2018; 9:525.

26. Lin LC, Lee MW, Wei RC, et al. Mozzart K.448 listening decreased seizure recurrence and epileptiform discharges in children with first unprovoked seizures: a randomized controlled study. BMC complement alter med. 2014; 14:17.

27. Turpin G, Siddle DA. Cardiac and forearm plethysmographic responses to high intensity audiotory stimulation. Biol psychol 1998; 6: 267-281.

28. Chen SC, Yeh ML, Chang HJ, et al. Music, heart rate variability, and symptom clusters: a comparative study. Supportive care in cancer 2020; 28: 351-360.

Received: November, 20, 2020

Accepted: January, 19, 2021 